\title{
The Effect of Insulin Like Growth Factor-1 on Recovery of Facial Nerve Crush Injury
}

\author{
Asuman Feda Bayrak $\cdot$ Yuksel Olgun² $\cdot$ Ayla Ozbakan ${ }^{3} \cdot$ Safiye Aktas $^{4} \cdot$ Can Ahmet Kulan $^{5} \cdot$ Gonca Kamaci $^{6}$ \\ Emine Demir ${ }^{7} \cdot$ Osman Yilmaz $^{6} \cdot$ Levent Olgun $^{7}$ \\ ${ }^{1}$ Otolaryngology Department, Izmir Ataturk Training and Research Hospital, Izmir; ${ }^{2}$ Otolaryngology Department, Dokuz Eylul University \\ Medical Faculty, Izmir; ${ }^{3}$ Otorhinolaryngology Department, Kutahya Simav State Hospital, Kutahya; ${ }^{4}$ Basic Oncology Department, Dokuz Eylul \\ University, Institue of Oncology, Izmir; ${ }^{5}$ Neurology Department, Izmir Bozyaka Training and Research Hospital, Izmir; ${ }^{6}$ Dokuz Eylul University, \\ Animal Laboratory, Izmir; ${ }^{7}$ Otorhinolaryngology Department, Izmir Bozyaka Training and Research Hospital, Izmir, Turkey
}

Objectives. The aim of this study is to investigate the efficacy of locally applied insulin-like growth factor 1 (IGF-1) on the recovery of facial nerve functions after crush injury in a rabbit model.

Methods. The rabbits were randomly assigned into three groups. Group 1 consisted of the rabbits with crush injury alone; group 2, the animals applied saline solution onto the crushed facial nerve and group 3, IGF-1 implemented to the nerve in the same manner. Facial nerve injury was first electrophysiologically studied on 10th and 42nd days of the procedure. The damage to the facial nerves was then investigated histopathologically, after sacrification of the animals.

Results. In the electrophysiological study, compound muscle action potential amplitudes of the crushed nerves in the second group were decreased. In pathological specimens of the first and second groups, the orders of axons were distorted; demyelination and proliferation of Schwann cells were observed. However, in IGF-1 treated group axonal order and myelin were preserved, and Schwann cell proliferation was close to normal $(P<0.05)$.

Conclusion. Local application of IGF-1 in a slow releasing gel was found efficacious in the recovery of the facial nerve crush injury in rabbits. IGF-1 was considered worthy of being tried in clinical studies in facial nerve injury cases.

Keywords. Insulin-Like Growth Factor I; Facial Nerve Injuries; Therapy; Animal Model

\section{INTRODUCTION}

The facial nerve is the motor nerve of facial expressions and loss of its function leads some aesthetic and emotional problems. Nerve has a long and complicated course from the brainstem to the facial musculature. As well as most of the otological and otoneurological procedures, surgeries of the parotid gland and the face are conducted around the facial nerve. So that, it is vulnerable to iatrogenic injuries. According to the severity of traumatic

- Received July 15, 2016

Revised December 30, 2016

Accepted January 9, 2017

- Corresponding author: Asuman Feda Bayrak

Otolaryngology Department, Izmir Ataturk Training and Research Hospital, Basin Sitesi Mah., Izmir 35360, Turkey

Tel: +90-505-398-88-06, Fax: +90-232-350-29-97

E-mail: fedabolat@yahoo.com insult, affection of function may differ from slight disfigurement to total loss of function [1].

Insulin-like growth factor 1 (IGF-1) is a naturally produced peptide which is shown to be synthesized within the brain and peripheral nerves. It is also found to be a trophic factor for various tissues. IGF-1 receptors were shown in neural tissues of reptiles, amphibian, and mammals such as rats, rabbits, and chicken. IGF-1 stimulates the development and growth of neurons and glial cells [2-4]. Moreover, IGF-1 was shown to promote neurite outgrowth and neuronal survival. The expression of IGF-1 in the nervous system was investgated by immunohistochemical techniques in rats. Following crush injury of a motor nerve, accumulation of IGF-1 immunoreactive material within the damaged area was shown invitro by Nachemson et al. [5]. Regeneration of the peripheral nerves after injury seems to be enhanced by the release of trophic factors. These factors stimulate the sprout-

Copyright () 2017 by Korean Society of Otorhinolaryngology-Head and Neck Surgery.

This is an open-access article distributed under the terms of the Creative Commons Attribution Non-Commercial License (http://creativecommons.org/licenses/by-nc/4.0)

which permits unrestricted non-commercial use, distribution, and reproduction in any medium, provided the original work is properly cited. 
ing of axons as well increased survival of neurons. IGF-1 is one of these factors. Among these molecules, IGF-1 seems to be promising. Schwann cells of the uninjured motor nerves express a little amount of IGF-1. However, after a traumatic injury, IGF1 concentrations increase, and it is excreted into the extracellular space. It exerts an insulin-like and trophic effect not only on the neural tissues but also on muscle and connective tissues. It is found to accelerate myelination and axonal regrowth in vivo [5]. The aim of this study is to investigate the efficacy of locally administered IGF-1 on the recovery of facial nerve functions after a crush injury.

\section{MATERIALS AND METHODS}

This study was conducted in Animal Research Laboratory of Dokuz Eylul University, between 24 June and 29 August 2013. Twenty adult New Zealand rabbits weighed 1,550-2,200 gr were recruited for the study. All animals were kept in the same environmental condition throughout the study with free access to water and food. Standard rabbit foods were provided for animals. The approval of Animal Ethical Committee of the University was obtained before the study (No. 22.05.2013/58/2013).

Animals were assigned into three groups. Right facial nerves of all animals were dissected and clamped for 30 seconds to make a crush injury. The first group consisted of the rabbits which have crush injury alone $(\mathrm{n}=7)$. The second group had crush injury plus locally applied $3 \mathrm{mg}$ of porcine skin gel soaked with $1 \mathrm{~mL}$ saline $(\mathrm{n}=7)$, and the third group was the study group with crush injury plus locally applied $3 \mathrm{mg}$ porcine skin gel soaked with $1 \mathrm{~mL}$ (100 $\mu \mathrm{g})$ of IGF-1 (mecasermin; Increlex, Ipsen Biopharmaceuticals, Inc., Basking Ridge, NJ, US) ( $\mathrm{n}=7$ ).

On the 10th and 42nd days, the animals were anesthetized with intramuscular ketamine hydrochloride $(35 \mathrm{mg} / \mathrm{kg})$ and xylazine hydrochloride $(5 \mathrm{mg} / \mathrm{kg})$ before the electrophysiologic examinations. So that, the electrophysiological study of facial nerves could be performed on both sides of the faces of the animals. As electrophysiological changes do not appear on electromyography (EMG) until 10 days, we decided to make the first examination on the 10th day. To see the regenerative changes on EMG, we performed the second test on the 42nd day. All animals were sacrificed after the electrophysiologic examinations were

\section{H I G G H L L I}

- Local application of insulin-like growth factor 1 (IGF-1) was found efficacious in the recovery of the facial nerve crush injury in rabbits.

- Electrophysiologic studies can be used in animal model of facial injury.

- IGF-1 may be applied for treatment of facial paralysis. completed. Both right and left extratemporal facial nerves were cut and histopathologically investigated by light microscopy.

\section{Surgical procedure}

A right vertical preauricular incision was done. After dissecting soft tissues, parotid gland was mobilized to anterior, and the main trunk of the facial nerve was found after emerging from temporal bone and was gently dissected. By using a vascular clamp (Dietrich bulldog clamp, CODMAN, Codman \& Shurtleff inc., Paramount, MA, US), 150 gr of engaging force was applied to the nerve trunk for 30 seconds. A silk thread was loosely tied around the nerve body at both proximal and distal sites of the injury (Fig. 1). For the first group, the wound was closed without doing anything further. For the second group, saline solution, and for the third group, IGF-1 solution were locally applied as described above (Fig. 2) and then the wound was closed.

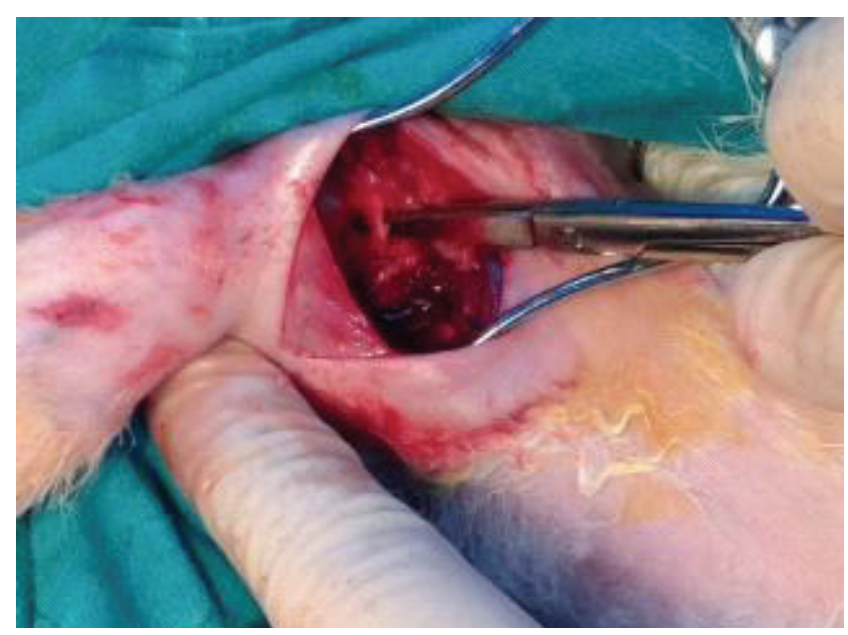

Fig. 1. Surgical procedure is seen as a silk thread was loosely tied around the nerve proximal and distal site to make a crush the injury of the rabit's facial nerve.

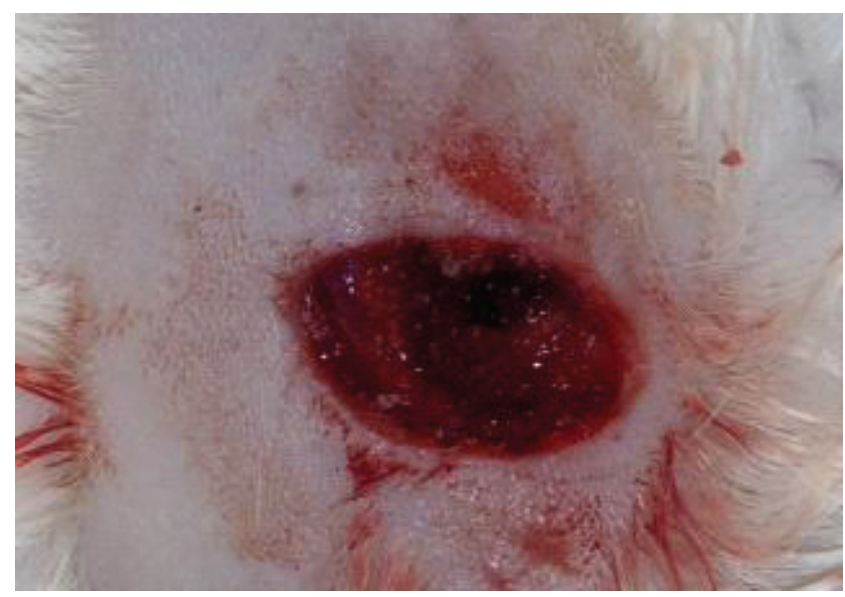

Fig. 2. Insulin-like growth factor 1 solution was locally applied with porcine skin gel was applied to the third group (study group). 


\section{Electrophysiological procedure}

All electrophysiological recordings were completed under intramuscular ketamine hydrochloride $(5 \mathrm{mg} / \mathrm{kg}$ ) anesthesia. The right and the left facial nerves were separately tested for each animal. Surface electrodes were placed onto nasal muscle, nasal tip (reference electrode) and auricula (ground electrode). Facial nerves were supramaximally stimulated at the mastoid apex, and motor responses of nasal muscles were recorded. Amplitudes and latencies of compound muscle action potentials of the facial nerves on both the crushed (right) and noncrushed sides were compared. Test results were compared between groups and within groups.

\section{Follow-up}

All animals were kept at same conditions, and they had free access to water and food. They were visually inspected twice weekly for the movement of vibrissae to ensure their survival. One of the animals was lost.

\section{Sacrification of the animals and harvesting the facial nerves}

Six weeks after crush injury of facial nerves, all animals were anesthetized with the same protocol. Crushed right facial nerves were dissected and harvested between the silk ties by using previous incisions. A similar neck incision was done on the left side of each animal and left facial nerve was dissected. Afterward, left facial nerve sample of the same length also harvested. All cuts on facial nerves were achieved with a number 15 surgical blade. Nerve samples were laid down on parafilm blocks.

All neural tissues were stained with either hematoxylin eosin or special gomori trichrome and examined under light microscopy. In histopathological examination, axonal order, structure of myelin sheath, the status of Schwann cells, existence of angiogenesis, thickness of the epineurium and extensiveness of collagen were noted. The thickness of epineurium was recorded as the micrometer. The number of vacuoles was counted per 100 times high power field. The degree of Schwann cell proliferation was recorded as low, medium or high and collagenization as none, low, medium or high.

\section{Statistical analysis}

All the data was analyzed by using SPSS ver. 15.0 (SPSS Inc., Chicago, IL, USA). For the comparison of the electrophysiologic findings on the 10th and 42nd days, Kruskal-Wallis test was used. The Mann-Whitney $U$-test was used for the evaluation of

Table 1. Electrophysiological findings of the facial nerves in all groups

\begin{tabular}{lcclcc}
\hline \multirow{2}{*}{ Group } & \multicolumn{2}{c}{ Motor latencies $(\mathrm{ms})$} & & \multicolumn{2}{c}{ Amplitudes $(\mu \mathrm{V})$} \\
\cline { 2 - 3 } \cline { 5 - 6 } & 10th Day & 42nd Day & & 10th Day & 42nd Day \\
\hline 1st & $1.40 \pm 0.15$ & $1.64 \pm 0.45$ & & $1.61 \pm 1.32$ & $1.95 \pm 0.62$ \\
2nd & $1.42 \pm 0.11$ & $1.47 \pm 0.20$ & & $1.87 \pm 0.95$ & $2.37 \pm 0.89$ \\
3rd & $1.44 \pm 0.16$ & $1.40 \pm 0.23$ & & $2.93 \pm 1.48$ & $2.99 \pm 1.38$ \\
\hline
\end{tabular}

intergroup differences. Wilcoxon test was used in the evaluation of intragroup time and side variables. The median values were given. The statistical significance was accepted to be $P<0.05$.

Histopathological findings were analyzed by chi-square test. Axonal order, degree of demyelination, the number of Schwann cells, appearance angiogenesis, the thickness of the epineurium and existence of collagen parameters were estimated during the histopathological investigation.

\section{RESULTS}

\section{Electrophysiologic findings}

The amplitudes of facial nerve responses at the crushed side were significantly lower in the second group on day ten compared with the third group $(P<0.05)$. Motor latencies of the three groups were not different at 10th and 42nd days (Table 1 ).

\section{Histopathological findings}

All neural tissues stained with either hematoxylin eosin or special gomori trichrome were investigated by light microscopy and axonal order, structure of myelin sheath, status of Schwann cells, existence of angiogenesis, thickness of the epineurium and presence of collagen were noted. The thickness of epineurium was recorded as the micrometer. The number of vacuoles were counted per 100 times high power field. The degree of Schwann cell proliferation was recorded as low, medium or high, and collagenization as none, low, medium or high.

In all groups, noncrushed left facial nerve specimens were evaluated first. Axons were in order. Myelination, Schwann cell proliferation, collagenization and the thickness of the epineurium were all within normal limits. Upon evaluation of crushed right facial nerves of groups 1 and 2, we reached the findings below: the orders of the axons were irregular. Myelination was diminished, and Schwann cell proliferation was more evident. Epineurium was found to be thinned, and collagenization was widespread. On the contrary, in study group (locally IGF applied group) axonal order was less disturbed. Both myelination and Schwann cell proliferation were close to normal. Epineurium was also normal, and the invasion of collagen was in a lesser degree.

Locally applied IGF-1 was found to reduce the damage of the facial nerve after crush injury. In the third group, vacuolization was less evident than the second group as well as the myelination and the collagenization (Fig. 3) $(P<0.001)$. In comparison

Table 2. The summary of histopathological findings of all groups

\begin{tabular}{lccccc}
\hline Group & $\begin{array}{c}\text { No. of } \\
\text { animal }\end{array}$ & $\begin{array}{c}\text { Epineurium } \\
\text { thickness }(\mu \mathrm{m})\end{array}$ & $\begin{array}{c}\text { No. of } \\
\text { vacuoles }\end{array}$ & $\begin{array}{c}\text { Schwann cell- } \\
\text { proliferation }\end{array}$ & Axons \\
\hline 1st & 6 & $40.83(38-45)$ & $1.00(0-3)$ & Low & Regular \\
2nd & 7 & $29.50(27-32)$ & $28.17(16-44)$ & High & Irregular \\
3rd & 7 & $54.86(52-57)$ & $5.86(2-11)$ & High & Regular \\
\hline
\end{tabular}

Values are presented as number or mean (range). 

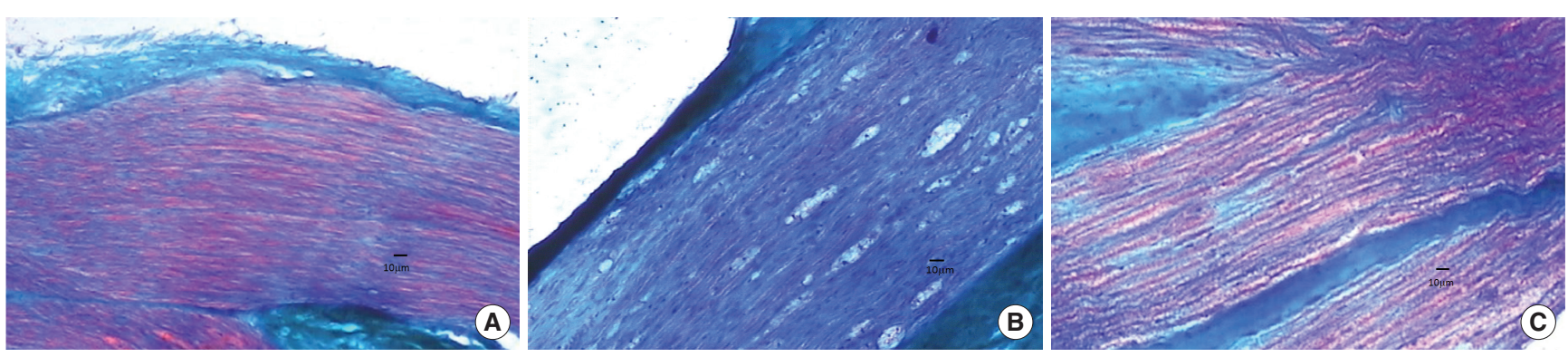

Fig. 3. (A) Left nerve without trauma, normal appearence. (B) Group 2 (salin applied group) right nerve with crushed injury. The order of axons degenerated, myelinization is reduced. Schwan cell proliferation is increased (medium grade). Epineurium is thinner, kollagenization is increased. (C) Group 3 (insulin-like growth factor applied group) right nerve with crushed injury, reduce damage can be seen. The order of axons has become normal. Myelinization has improved. Schwann cell proliferation and kollagenization have been low grade. The epineurium has become normal (trichrome staining, $\times 100$ ).

to the first and the second groups, there were not any statistically significant differences in these parameters $(P>0.05)$ (Table 2$)$.

\section{DISCUSSION}

Facial paralysis is known to cause severe problems in patient's appearance, with severe impact on individual's life together with psychological and social problems. Crush injuries of facial nerve can occur due to external traumas or iatrogenic causes. Like many otological and otoneurological procedures, parotid surgery and maxillofacial interventions also carry the risk of injuring facial nerve.

When the injury is slight, the only pathologic mechanism is the blockage of axoplasmic flow which leads a temporary facial paralysis. With the return of axoplasmic flow, this paralysis can recover without any sequela.

However, in more severe injuries, endoneurium can be damaged, and even some axons can be permanently disrupted. In this case, recovery of facial functions should not be proper and disturbing symptoms such as synkinesis, mass movements or crocodile-tear syndrome can be seen. These symptoms are attributed to misdirection of regenerated axons within damaged neural tubules.

Recovery is related with severity of traumatic insult as well as the severity of the symptoms. When the compression-induced ischemia is more prominent, nerve healing is expected to be more rapid and recovery, thus less problematic. If the mechanical disruption of the axons are in excess, healing should take longer time and only with sequela [1].

Some authors prefer rats in order to study the injury of peripheral nerves [6,7]. However, atypical posttraumatic axonal reactions can be seen in rats. So that, we chose rabbits to investigate the crush injury of facial nerve. Anatomy of the facial nerve in rabbit resembles human anatomy. In contrast with rats, a marked chromolysis and complete remission of paralysis were shown within a few weeks after crush injury [8].
One of the most important aspects of follow-up is to predict the prognosis. This is necessary not only for counseling the patient, but also for planning future interventions in totally paralytic and progressive cases. For this purpose, some qualitative and quantitative methods as well electrophysiologic and morphometric analyses were described. In this study, we selected motor responses of facial nerves as it is an objective electrophysiologic test in order to guess the prognosis. Electrophysiologic responses were used in peripheral nerve injury models of various animals with varying success $[9,10]$.

After any traumatic insult, prevention of severe edema formation and inhibition of inflammatory reactions are expected to shorten the recovery time, together with better functional results. For this aim, many medications have been tried such as corticosteroids, adrenocorticotrophic hormone, vasodilators, vitamins, and antiviral agents.

There are plenty of studies in which various molecules have been tried for treatment of nerve injury. Topdag et al. [11] claimed that a tumor necrosis factor (TNF)- $\alpha$ antagonist (etanercept) was effective in nerve crush injury model. Jang et al. [12] found that topical dexamethasone enhanced the regeneration. Regeneration of peripheral nerves after crush injury is a very complex issue and various factors may affect the recovery. Some medications, neural stem cells and electrical stimulation have been all tried to enhance the recovery. Among many trials, growth factors such as brain derived neural growth factor, ganglion derived neural growth factor, and fibroblast growth factor (FGF) were found beneficial in some in vivo studies; though they have not been studied in clinical practice up to date [11-14].

IGF-1 and IGF-2 receptors were found in neural tissues of aves, reptiles, amphibia, and mammals. IGF-1 stimulates the development and growth of neurons and glial cells. Its serum level is controlled by growth hormon. Moreover, IGF-1 was shown to promote neurite outgrowth and neuronal survival. However, after an injury IGF-1 reactive material is overexpressed. There are some in vitro and in vivo studies, which indicate that IGF-1 promotes nerve regeneration $[4,5,15]$. Fex Svenningsen and Kanje 
[16] showed that IGF-1 increased Schwann cell proliferation surrounding the myelinated nerve fibers in peripheral nerve cultures. These authors have reported that IGF-1 is expressed in human neural stem cells and is potentially a neurotrophic and neuroprotective substance. So that IGF-1 may stimulate neurite outgrowth and provide neuroprotection against neurotoxic agents [17].

Thanos et al. [18] found that local application of $50 \mu \mathrm{gr} / \mathrm{mL}$ IGF-1 on crossed facial nerve grafts led to improvement in orbicularis oris functions. They also proved that myelination, axonal regeneration, and diameters of the axons were improved. Emel et al. [19] investigated the effects of local IGF-1 application on crush injury of sciatic nerve in rats. They pointed out that sciatic function index and sensory function had recovered. The diameters of axons and the thickness of myelin sheaths had significantly increased.

In a review of Werner and LeRoith [20], IGF-1 is referred as a neuropeptide, which has some biological activities such as enhancing neuronal survival, neurogenesis, angiogenesis, excitatory, and inhibitory neurotransmission. It was said to be locally produced in central nervous system in addition to the portion coming from peripheral circulation via blood-brain barrier. Tiangco et al. [21] found that in a model of end to side nerve anastomosis, continuous application of IGF-1 with an osmotic pump enhances the rate of axonal regeneration and functional recovery of paralyzed muscles.

D'ercole et al. [22] claim that in mutant hide mice IGF-1 has a central role in the growth and development of the central nervous system. It was found to stimulate myelination as well as oligodendrocyte development and neuronal survival. On the contrary, Yuan et al. [23] found IGF-1 ineffective in the prevention of death of motor neurons secondary to avulsion or axonal transection in newborn rats.

Ozdinler and Macklis [24] studied corticospinal motor neurons in vitro and found that IGF-1 improves axonal out growth. Kimpinski and Mearow [25] have worked on sensorial nerves and showed that IGF-1 causes neuritic growth similar to nerve growth factor (NGF). When applied on cell bodies, IGF enhances distal neurite growth within the compartment which contains NGF.

Skouras and Angelov [1] claimed that combination of manual mechanical stimulation with the local IGF-1 application was an effective method in recovery after facial nerve anastomosis. Kiryakova et al. [26] also reached similar conclusions in a study conducted on rats. They concluded that IGF-1 application led to the increase of terminal Schwann cells in the neuromuscular junction. Our histopathologic findings are similar with many of these results and point out that IGF-1 application is beneficial on hastening the recovery after crush injury of the facial nerve. Since continuous release of IGF- 1 is required for the nerve regeneration, the way of application is an important issue. Some authors had to use osmotic pumps to deliver various growth factors to the site of injury. However, it is rather a difficult way for animal experiments and also in clinical applications. Compliance is not very high, and also it is relatively expensive. Another method of continuous controlled release of molecules may be to use hydrogels. These biodegradable gels make a complex with drugs. While polymers decrease in size, these drugs are continuously released. Gnavi et al. [27] used hydrogel for vascular endothelial growth factor and found that regeneration of neural tissues was enhanced. Matsumine et al. [14] used gelatin hydrogel and micropipettes to deliver basic fibroblast growth factor and found this method to be effective. Lee et al. [28] used IGF-1 soaked gelatin sponges onto the round window in a guinea pig model of acoustic trauma which was severe enough to prolong auditory brain response (ABR) values. These findings were histopathologically supported with enhanced recovery of outer hairy cells.

Nakagawa et al. [13] found that majority of sudden deafness patients who do not respond to corticosteroids benefited from the local application of IGF-1. A piece of IGF-1 soaked gelatin hydrogel had been inserted in the round window niche in this group of patients. Komobuchi et al. [29] studied the effects of basic fibroblast growth (b-FGF) factor on intratemporal facial nerve injury model in guinea pigs. They histopathologically and electrophysiologically proved that application of b-FGF alone, without any supporting material, does not have any beneficial effect on recovery; however, its application in a hydrogel base led to better recovery within 6 weeks. Our method of application gelatin-based hydrogel to deliver to the site of injury for a given period is similar to the study cited above.

The prediction of prognosis after crush injury of the facial nerve is important in the treatment planning. Inspection is a straightforward and reliable method; but also needs documentation. Different electrophysiologic and histomorphometric analysis have been developed to evaluate the functional recovery and neuronal regeneration. Electroneurographic (ENG) and EMG recordings are most widely used techniques $[9,10,30]$. So we used electroneurographic recordings. Volk et al. [10] investigated the value of different electrophysiologic parameters in 259 patients for the determination of the prognosis. They found that apart from initiation of treatment and House Brackman (HB) grading, electrophysiologic investigtions and stapedius reflex tests are highly important indicators in the assessment of recovery time in facial paralysis.

When the facial nerve is damaged either demyelination or axonal degeneration can occur. The crush injury model we made causes axonal damage, so the decrease in amplitudes of motor responses must be the leading electrophysiologic feature. The prolongation of motor latencies indicates demyelination. So that, the latencies were expected to be quite normal.

In our study, we found remarkable amplitude attenuation in the group which was applied only saline. In the IGF-1 group, no attenuation of the amplitudes did occur. This result points to the capability of IGF to improve the recovery of facial nerve injury.

The histopathologic results supported the electrophysiologic data. The orders of the axons were irregular, myelination was di- 
minished, and Schwann cell proliferation was more evident in the non-IGF groups. On the contrary in the study group (locally IGF applied group) axonal order was less disturbed, as well as myelination. Schwann cell proliferation was close to normal. Epineurium was normal, and collagenization was in a lesser degree.

These findings reveal that IGF- 1 is beneficial in the recovery of facial nerve after injury. This animal study may contribute to the clinical studies and IGF-1 may be developed as a candidate drug in the future.

In conclusion, local application of IGF-1 in a slow releasing gel was found to be efficacious in the recovery of facial nerve crush injury in rabbits. Since this molecule is a natural peptide and considered to be beneficial in clinical use, it should be worthy of being tried in clinical drug studies on facial nerve injury cases.

\section{CONFLICT OF INTEREST}

No potential conflict of interest relevant to this article was reported.

\section{REFERENCES}

1. Skouras E, Angelov DN. Experimental studies on post-transectional facial nerve regrowth and functional recovery of paralyzed muscles of the face in rats and mice. Anatomy. 2010 Oct;4:1-27.

2. Yakar S, Adamo ML. Insulin-like growth factor 1 physiology: lessons from mouse models. Endocrinol Metab Clin North Am. 2012 Jun;41(2):231-47.

3. Ishii DN, Glazner GW, Pu SF. Role of insulin-like growth factors in peripheral nerve regeneration. Pharmacol Ther. 1994 Apr-May;62 (1-2):125-44.

4. Rosenbloom AL, Rivkees SA. Off-label use of recombinant IGF-I to promote growth: is it appropriate? J Clin Endocrinol Metab. 2010 Feb;95(2):505-8.

5. Nachemson AK, Lundborg G, Hansson HA. Insulin-like growth factor I promotes nerve regeneration: an experimental study on rat sciatic nerve. Growth Factors. 1990;3(4):309-14.

6. Ter Laak MP, Brakkee JH, Adan RA, Hamers FP, Gispen WH. The potent melanocortin receptor agonist melanotan-II promotes peripheral nerve regeneration and has neuroprotective properties in the rat. Eur J Pharmacol. 2003 Feb;462(1-3):179-83.

7. Eriksson NP, Aldskogius H, Grant G, Lindsay RM, Rivero-Melian C. Effects of nerve growth factor, brain-derived neurotrophic factor and neurotrophin-3 on the laminar distribution of transganglionically fransported choleragenoid in the spinal cord dorsal horn following transection of the sciatic nerve in the adult rat. Neuroscience. 1997 Jun;78(3):863-72.

8. Costa HJ, Silva CF, Korn GP, Lazarini PR. Posttraumatic facial nerve regeneration in rabbits. Braz J Otorhinolaryngol. 2006 Nov-Dec;72 (6):786-93.

9. Sachs NA, Chang EL, Vyas N, Sorensen BN, Weiland JD. Electrical stimulation of the paralyzed orbicularis oculi in rabbit. IEEE Trans Neural Syst Rehabil Eng. 2007 Mar;15(1):67-75.

10. Volk GF, Klingner C, Finkensieper M,Witte OW, Guntinas-Lichius O. Prognostication of recovery time after acute peripheral facial palsy: a prospective cohort study. BMJ Open. 2013 Jun;3(6). pii: e003007.
11. Topdag M, Iseri M,Topdag DO, Kokturk S, Ozturk M, Iseri P.The effect of etanercept and methylprednisolone on functional recovery of the facial nerve after crush injury. Otol Neurotol. 2014 Aug;35(7): 1277-83.

12. Jang $\mathrm{CH}$, Cho YB, Choi CH, Jang YS, Jung WK. Effect of topical dexamethasone in reducing dysfunction after facial nerve crush injury in the rat. Int J Pediatr Otorhinolaryngol. 2014 Jun;78(6):9603.

13. Nakagawa T, Sakamoto T, Hiraumi H, Kikkawa YS, Yamamoto N, Hamaguchi K, et al. Topical insulin-like growth factor 1 treatment using gelatin hydrogels for glucocorticoid-resistant sudden sensorineural hearing loss: a prospective clinical trial. BMC Med. 2010 Nov;8:76.

14. Matsumine H, Sasaki R, Tabata Y, Matsui M, Yamato M, Okano T, et al. Facial nerve regeneration using basic fibroblast growth factor-impregnated gelatin microspheres in a rat model. J Tissue Eng Regen Med. 2016 Oct;10(10):E559-E567.

15. Cheng HL, Russell JW, Feldman EL. IGF-I promotes peripheral nervous system myelination. Ann NYAcad Sci. 1999 Sep;883:124-30.

16. Fex Svenningsen A, Kanje M. Insulin and the insulin-like growth factors I and II are mitogenic to cultured rat sciatic nerve segments and stimulate $[3 \mathrm{H}]$ thymidine incorporation through their respective receptors. Glia. 1996 Sep;18(1):68-72.

17. Zhang H,Wei YT, Tsang KS, Sun CR, Li J, Huang H, et al. Implantation of neural stem cells embedded in hyaluronic acid and collagen composite conduit promotes regeneration in a rabbit facial nerve injury model. JTransl Med. 2008 Nov;6:67.

18. Thanos PK, Tiangco DA, Terzis JK. Enhanced reinnervation of the paralyzed orbicularis oculi muscle after Insulin-like Growth Factor-I (IGF-I) delivery to a nerve graft. J Reconstr Microsurg. 2001 Jul;17 (5):357-62.

19. Emel E, Ergun SS, Kotan D, Gursoy EB, Parman Y, Zengin A, et al. Effects of insulin-like growth factor-I and platelet-rich plasma on sciatic nerve crush injury in a rat model. J Neurosurg. 2011 Feb;114(2): $522-8$.

20. Werner H, LeRoith D. Insulin and insulin-like growth factor receptors in the brain: physiological and pathological aspects. Eur Neuropsychopharmacol. 2014 Dec;24(12):1947-53.

21. Tiangco DA, Papakonstantinou KC, Mullinax KA, Terzis JK. IGF-I and end-to-side nerve repair: a dose-response study. J Reconstr Microsurg. 2001 May;17(4):247-56.

22. D'Ercole AJ, Ye P, O'Kusky JR. Mutant mouse models of insulin-like growth factor actions in the central nervous system. Neuropeptides. 2002 Apr-Jun;36(2-3):209-20.

23. Yuan Q,WuW, So KF, Cheung AL, Prevette DM, Oppenheim RW. Effects of neurotrophic factors on motoneuron survival following axonal injury in newborn rats. Neuroreport. 2000 Jul;11(10):2237-41.

24. Ozdinler PH, Macklis JD. IGF-I specifically enhances axon outgrowth of corticospinal motor neurons. Nat Neurosci. 2006 Nov;9 (11):1371-81.

25. Kimpinski K, Mearow K. Neurite growth promotion by nerve growth factor and insulin-like growth factor-1 in cultured adult sensory neurons: role of phosphoinositide 3-kinase and mitogen activated protein kinase. J Neurosci Res. 2001 Mar;63(6):486-99.

26. Kiryakova S, Sohnchen J, Grosheva M, Schuetz U, Marinova TS, Dzhupanova R, et al. Recovery of whisking function promoted by manual stimulation of the vibrissal muscles after facial nerve injury requires insulin-like growth factor 1 (IGF-1). Exp Neurol. 2010 Apr;222(2):226-34.

27. Gnavi S, di Blasio L,Tonda-Turo C, Mancardi A, Primo L, Ciardelli G, et al. Gelatin-based hydrogel for vascular endothelial growth factor release in peripheral nerve tissue engineering. J Tissue Eng Regen Med. 2017 Feb;11(2):459-70.

28. Lee KY, Nakagawa T, Okano T, Hori R, Ono K, Tabata Y, et al. Novel 
therapy for hearing loss: delivery of insulin-like growth factor 1 to the cochlea using gelatin hydrogel. Otol Neurotol. 2007 Oct;28(7): 976-81.

29. Komobuchi H, Hato N,Teraoka M,Wakisaka H,Takahashi H, Gyo K, et al. Basic fibroblast growth factor combined with biodegradable hydrogel promotes healing of facial nerve after compression injury: an experimental study. Acta Otolaryngol. 2010 Jan;130(1):173-8.

30. Grosheva M, Wittekindt C, Guntinas-Lichius O. Prognostic value of electroneurography and electromyography in facial palsy. Laryngoscope. 2008 Mar;118(3):394-7. 